\title{
REALISMO MACABRO EN LA NOVELA NOLI ME TANGERE DE JOSÉ RIZAL A LA LUZ DEL POEMA ALMAS MUERTAS DE NIKOLAI GOGOL
}

\author{
MACABRE REALISM IN JOSÉ RIZAL'S NOVEL NOLI ME TANGERE \\ IN THE LIGHT OF NIKOLAI GOGOL'S POEM DEAD SOULS
}

\author{
STEPhan Lipke \\ Universidad Estatal de Tomsk / Instituto Santo Tomás, Moscú \\ Rusia \\ stephanlipkesj@gmail.com
}

\begin{abstract}
Resumen: En este artículo se analiza la novela Noli me tangere de José Rizal en el contexto de la liberación de Filipinas del imperio español. Tal como Nikolai Gogol no solo describe realísticamente en Almas muertas los sufrimientos de Rusia, sobre todo de los campesinos, y una de sus causas, la falta de educación de las clases altas o medias, sino que también se burla de ello, al igual que la "novela tagala", de Rizal, la cual comparte la misma tradición grotesca, suma la irrisión a la descripción realista de la opresión del pueblo filipino. A la luz de la historia de la literatura mundial, como la presentan Mikhail Bakhtin, Iuri Mann y Franca Beltrame, y con la ayuda de la crítica de E. San Juan, Jr., se muestra que ese realismo va más allá del aspecto políticosocial. Para los autores, el aspecto macabro es importante, es decir, la transgresión desvergonzada, absurda y ridícula del ámbito de los muertos por parte de los vivos.
\end{abstract}

Palabras clave: Nikolai Gogol , José Rizal, Rusia, Filipinas, realismo, grotesco, macabro.

\begin{abstract}
In this study we analyze Noli me tangere by José Rizal, in the context of the Filipino liberation movement. Just like Nikolai Gogol's poem Dead Souls not only describes realistically the sufferings of Russia, and most of all, of the serf farmers, and one of its main reasons, the lack of education in the middle and higher classes, but also makes fun of it, likewise, Rizal's "novela tagala", which belongs to the same artistic tradition of the grotesque, combines the realistic description of the Filipino people's suffering with ridicule. With the help of the history of world literature, as presented by Mikhail Bakhtin, Yuri Mann and Franca Beltrame, and in the light of E. San Juan, Jr.'s critical method we show that realism in both writers' works goes beyond political and social aspects and is strongly imbued with the macabre aspect, i.e. the shameless, absurd and ridiculous transgression of the realm of the dead by the living.
\end{abstract}


Keywords: Nikolai Gogol', José Rizal, Russia, Philippines, realism, grotesque, macabre.

Recibido: 21/10/2020. Aceptado: 22/12/2020.

\section{Introducción: Rizal, la literatura universal y la literatura rusa}

Cuando José Rizal publicó su Noli me tangere: Novela tagala (Berlín,
1887), su amigo José Cecilio le comentó que estaba escrita al estilo de la literatura rusa (Castroverde, 2013: 10). Y cuando el protagonista Crisóstomo Ibarra le dice que ha viajado por varios países europeos hasta "la Polonia rusa”, parece que a los interlocutores el único país que les interesa es esa "Polonia rusa". Aunque sería más lógico que alguien le preguntara a Ibarra si ha conocido a un español, le dijera si ha conocido a "un polaco de Va... Varsovia, llamado Stadtnitzki” (Rizal, 1983: 47). Está claro que esa "Polonia rusa" tiene un significado especial. No es que acaso el interlocutor haya conocido a Stadtnitzki en España. Es que muchos polacos tienen el mismo destino de muchos filipinos, el exilio, porque la Polonia oprimida por el imperio ruso tiene el mismo destino que las Filipinas oprimidas por el imperio español.

En realidad, Rizal tiene en común con los grandes autores rusos la importancia de los viajes por Europa: Para Gogol, su viaje por Alemania, Suiza, Francia y, sobre todo Italia, tuvo mucha importancia. Turguéniev y Dostoevsky pasaron mucho tiempo en Suiza, Inglaterra, Francia, Alemania e Italia.

Es más, al igual que los autores rusos del siglo XIX más importantes, Rizal también está ligado a las grandes tradiciones de la literatura mundial: Pushkin (1975: 65), en su cuento El fabricante de ataúdes, se refiere explícitamente a los sepultureros en Hamlet. Gogol, cuando escribe su poema Almas muertas ${ }^{1}$, en gran parte en el extranjero (Opul'skaia, 1984: 309), se refiere a la Divina comedia hablando de Virgilio y Dante (Gogol, 1984: 143). Turguéniev (1964: 169-192) dedica un ensayo programático a Hamlet

${ }^{1}$ Aunque está escrita en prosa, la obra se llama "poema", como el Yevgueni Oneguin de Pushkin se llama "novela en versos" (Alexandrov, 2010: 14). La denominación "poema" subraya la conexión entre Almas muertas y el poema Divina comedia (Mann, 1996: 317). 
y Don Quijote. Y Dostoevsky se refiere al Don Quijote cuando en El idiota describe al príncipe Myshkin como un caballero idealista en sus peregrinajes que en vano trata de salvar a su dama, Nastasia Filippovna (Holquist, 1984: 131-132; Bakhtin, 1984: 158). Con el poema de Pushkin El caballero pobre, ${ }^{2}$ Dostoevsky (1972-1990: VIII, 205-209) inserta al príncipe en la tradición rusa de reflexiones sobre la quijotería (Novikova 2016: 84-90). Dostoevsky (1972-1990: XXV, 47-51) se refiere también a Don Quijote en un artículo Metterniches y Don-Quijotes de 1877, en el cual contrapone posiciones realistas e idealistas en la política.

Como los citados autores, Rizal participa en las grandes tradiciones de la literatura mundial. Así, escribe sus novelas bajo la influencia de $L a c a-$ baña del tío Tom (Zaide/ Zaide, 1984: 88) o (como en el caso de El Filibusterismo) del Conde de Montecristo (Zaide/ Zaide, 1984: 32). Debido a esto, es lógico que el autor de Noli me tangere sea heredero también de las grandes obras de la literatura universal de los siglos anteriores. Por ejemplo, Rizal (1983: 129-130) se refiere al Purgatorio de la Divina comedia de Dante y a Virgilio. Cita también las palabras del Inferno de Dante: "Lasciate ogni speranza voi ch'entrate" (Rizal, 1983: 211). Además, aunque E. San Juan, Jr. (1971: 10) tenga razón y estuviese equivocado en llamar a Rizal autor de un "Quijote tagalo", los peregrinajes del protagonista Don Crisóstomo Ibarra verdaderamente evocan al caballero de La Mancha: al igual que los peregrinajes de Don Quijote muestran la realidad de España en el tiempo de Cervantes, las aventuras de Ibarra, recién vuelto desde Europa, muestran la realidad de Filipinas en el tiempo de Rizal (Giménez, 1971: 5; Zaide/ Zaide, 1984: 104). En ese sentido Rizal, quien como los grandes autores rusos viajó por casi toda Europa, tiene lo que Dostoevsky (1972-1990: XXVI, 145) llama "receptividad universal".

El autor de Noli me tangere y El filibusterismo también tiene en común con los grandes autores rusos, sobre todo con Dostoevsky, que las tradiciones internacionales le sirven para entender qué es "lo otro" y qué significa, en cambio, pertenecer a su propia nación (San Juan, 2010: 42; Dostoevsky, 1972-1990: VIII, 358; VIII, 510; X, 516).

\footnotetext{
${ }^{2}$ Traducciones del ruso e italiano aquí y siempre del autor.
} 


\section{El realismo y lo grotesco}

Sin embargo, la conexión de Rizal con la tradición rusa va más allá. Especialmente, existen algunos elementos sombríos y macabros que unen a Rizal con la tradición rusa y, en particular, con Nikolai Gogol. Y tenemos la intención de presentar aquí la tesis de que uno de los aspectos principales de Noli me tangere es un "realismo macabro," heredado de las Almas muertas, de Gogol.

Es muy posible que Rizal conociera el poema de Gogol porque desde 1846 existían traducciones de Almas muertas al alemán (Nikanorova, 2011: 591) y desde 1854 al inglés (Kholkina, 2016: 239). Se sabe también que en 1893 Rizal encargó y en 1894 recibió las obras completas de Gogol en alemán, junto con algunas obras de Turguéniev (Ocampo, 1960: 31; 37). Si bien es cierto que esto no necesariamente significa que hubiese leído una parte de esas obras antes de escribir Noli me tangere, en verdad muestra que en cierto modo las conocía.

Con el concepto de "realismo macabro" nos referimos al hecho de que en una obra realista, como por ejemplo La cabaña del tío Tom, las atrocidades de la vida real se presentan de manera radicalizada para destacar con más intensidad sufrimientos que antes se ignoraban. Es común que autores como Victor Hugo, Charles Dickens o Herriet Beecher Stowe intensifiquen la percepción de la realidad, haciendo llorar a sus lectores. Aquí, en cambio, la radicalización consiste en que Gogol y Rizal se burlan de la realidad. Usan como forma artística la transgresión del mundo de los muertos por parte de los vivos, lo que significa una falta extrema, grotesca e ilógica de respeto hacia los muertos. Así se llega a una forma de risa carnavalesca, donde la presencia del tema de la muerte no conduce a una atmósfera de respeto y reverencia, sino a una de burla y desvergüenza (Bakhtin, 1984: 125-126). Así se observa, por ejemplo, en el Fabricante de ataúdes de Pushkin, en el diálogo de los sepultureros, en Hamlet y sobre todo en el Decamerón. Las obras de Gogol y de Rizal son realistas también porque, a diferencia de otras obras del siglo XIX, sobre todo, de la época romántica, no hay ninguna transgresión de la frontera por parte de los muertos, ninguna visión de fantasmas u otro avenimiento sobrenatural.

Gogol -como Rizal- sabe bien que en su país hay muchas cosas por las que llorar, pero las describe burlándose de ellas. Así, cuando describe 
los viajes de Chíchikov, lo hace con exageración grotesca, diciendo que en los caminos hay primero polvo, después empieza la lluvia y de repente ese polvo se convierte en fango (Gogol, 1984: 40). También la descripción de las moscas en la casa de la terrateniente Korobochka resalta cómo todo está muy sucio en esa hacienda (Gogol, 1984: 45-46). Eso recibe una nota de risa cuando dice que Chíchikov se despierta porque una mosca le ha entrado a su nariz y, consiguientemente, el protagonista tiene que estornudar (Gogol, 1984: 46).

En ese sentido, la atmósfera general de Noli me tangere recuerda a Almas muertas. A modo de ejemplo: Rizal (1983: 24) describe un puente en Binondo, el chinatown de Manila, que está "descompuesto por un lado durante seis meses e intransitable por el resto del año", es decir, como el camino en Almas muertas nunca está bien. Aquí eso puede causar situaciones irrisorias porque "los caballos en la temporada de calor aprovechan este permanente statu quo para desde allí saltar al agua, con gran sorpresa del distraído mortal que en el interior del coche dormita o filosofa sobre los progresos del siglo" (Rizal, 1983: 24³). La pintura blanca de las casas de Binondo imita "mal el granito" (Rizal, 1983: 51). Aquí el humor sarcástico está en los contrastes: el pasajero quiere tranquilidad - los caballos saltan; el pasajero piensa en el progreso - el puente está descompuesto; granito es un material sólido - la pintura solo lo imita.

También la casa de Capitán Tiago, el padre (legal) de la protagonista María Clara, se describe en una manera símil a esa: "No creemos que su dueño la haga derribar, porque de este trabajo ordinariamente se encarga allí Dios o la Naturaleza, que también tiene de nuestro gobierno muchas obras contradas" (Rizal, 1983: 24). Eso hace entender que en Filipinas es costumbre la destrucción lenta o repentina -por ejemplo por terremotosde lo que han construido los hombres. .

Ambos escritores ven que una causa de las desdichas de sus países es la ausencia de educación en general, sobre todo en las clases dirigentes. Y ambos la describen de modo tal que el lector se ríe. Por ejemplo, en Almas muertas el terrateniente Manilov llama a su hijo "Themistoklus" en vez de “Themistokles” (Gogol, 1984: 29). Eso muestra que no conoce bien el grie-

${ }^{3}$ Letras negritas aquí y en todo el texto de Rizal, S.L 
go, aunque finge conocerlo. También Manilov expresa que Themistoklus es muy culto y puede hacerse embajador. Lo demuestra preguntando a su hijo “¿cuál es la mejor ciudad en Francia?”, y ¿̇cuál es "la mejor ciudad en Rusia?” y “cicuál más?” (Gogol, 1984: 29). Lo que el hijo de ocho años sabe sobre las "mejores ciudades" de Francia y de Rusia (Rusia tenía dos, San Petersburgo y Moscú) hace creer a su padre que el chico es muy culto, aunque parece que ni siquiera conoce la palabra "capital". Eso ya es para reír, pero lo es aún más el momento en el que Manilov pregunta a Themistoklus si quiere hacerse embajador: "el criado, que estaba detrás, le limpió la nariz al embajador, y lo hizo con mucha razón, porque si no, habría caído en la sopa una gota bastante grande que no pertenecía allí" (Gogol', 1984: 29). Con todo eso Gogol se burla de las personas incultas de clase alta o media.

Lo mismo hace Rizal en Noli me tangere. Por ejemplo, un franciscano hace la afirmación absurda de que otro franciscano, Savalls (apellido de un político carlista, en vez de Schwartz, el franciscano real que describe la pólvora como primer europeo) había inventado la pólvora en el siglo séptimo. Un dominico lo corrige y le dice que esto ha ocurrido sólo en el siglo catorce. Después de eso, doña Victorina, una "doctora" -o sea: esposa de un médico (aunque se entiende después que no es un médico auténtico)pregunta "con gran interés" si Schwartz había inventado la pólvora "antes o después de Cristo" (Rizal, 1983: 38-39; cf. 401). Así se ve que las élites del país no son muy cultas y sólo gobiernan porque son españolas o, como doña Victorina, tagalas esposas de españoles.

Lo mismo se ve cuando Rizal cuenta cómo el alférez (comandante de la Guardia Civil) del pueblo de San Diego hace muchos años se había casado con otra tagala, doña Consolación. Ésta inicialmente no sabe pronunciar "Filipinas" (la "f" no se pronuncia en tagalo) sino que dice "Pilipinas". El alférez la quiere corregir, pero tampoco sabe explicar que la denominación "Filipinas" no deriva directamente del nombre español de don Felipe (osea el rey Felipe II), sino de la versión latina de su nombre, Philippus. Por eso, el alférez inventa la historia de que la gente culta en Madrid de los tiempos modernos ya reemplaza la "i" por la "e" y dice "menistro", mientras que "Filipinas" es una denominación más antigua (Rizal, 1983: 370-371). Así no sólo la ignorancia, sino también el lenguaje de los representantes de las clases superiores sugiere que no son cultos.

Esto se siente también cuando el padre Dámaso predica: emplea mal el 
latín. Dice, por ejemplo, "errarle es hominum" en vez de "errare humanum est” (Rizal, 1983: 297), e igualmente habla mal el tagalo. Dirige la palabra a los auditores así: "Maná capatir con cristiano" en vez de "Maña capatid sa Cristo"4 ("Hermanos y hermanas en Cristo": Rizal, 1983: 303). Así se ve que él no puede ser buen líder espiritual del pueblo, porque no conoce ni el idioma tradicional de la teología y las fuentes del saber ni el idioma de la gente.

Rizal subraya aún más el efecto ridículo, por ejemplo, con el hecho de que las ya citadas palabras de doña Victorina "antes o después de Cristo", son las últimas palabras de un capítulo (Rizal, 1983: 39) o por el escándalo que estalla cuando un hombre deja la iglesia tras el sermón tagalo del padre Dámaso porque, como dice, el sermón es “griego" (Rizal, 1983: 303).

El problema del lenguaje poco culto tiene importancia porque el idioma es uno de los instrumentos preferidos de estos personajes para definirse a sí mismos como miembros de las élites. Esto muestran las continuas tentativas del padre Dámaso de parecer culto usando el latín. La misma importancia puede tener el español. Así es de ridículo que doña Victorina, siendo tagala, en un cierto momento decida hablar como una andaluza (Rizal, 1983: 542).

Doña Consolación se describe como "orofea”, en vez de "europea” (Rizal, 1983: 369) o sea tan lejos de ser tagala que pronuncia " $\mathrm{f}$ " incluso cuando no hace falta. Cuando tortura a Sisa, arrestada en la casa del alférez, finge hablar mal el tagalo, su lengua materna (Rizal, 1983: 369). Pero cuando Sisa canta y sus canciones emocionan mucho a doña Consolación, ésta exclama "en perfecto tagalo, levantándose agitada -, iNo cantes! iMe hacen daño esos versos!" (Rizal, 1983: 373). Todo eso muestra que en el mundo de Noli me tangere el idioma es un instrumento que se usa para fingir pertenecer a las clases altas. Pero los que pertenecen a ellas no saben hablar bien ni son cultos, y esto es el objeto de burla de Rizal.

Así como Gogol quiere hacer que los lectores "reían tras lágrimas" (Beltrame, 1996: 67), Rizal escribe "Noli me tangere" para reír en vez de llorar (San Juan, 1971: 11).

Franca Beltrame (1996: 15) tiene razón cuando afirma que "Gogol' es un

\footnotetext{
${ }^{4}$ Hoy día, después de la reforma ortográfica, se escribiría "Mga kapatid sa Kristo”.
} 
escritor grotesco ejemplar”, y este elemento grotesco es fuerte también en Rizal. La tradición grotesca expresa estéticamente lo que dicen las brujas en el Macbeth (I, 1) de Shakespeare (1967: 53): "Fair is foul and foul is fair" (Beltrame, 1996: 60). Haciéndose parte de esa tradición, nuestros autores describen no sólo cómo alguna parte de un sistema que funciona mal, sino que lo que funciona mal -o sea una deformación parcial (Beltrame, 1996: 36) - se ha hecho dominante y ha llevado al sistema entero a funcionar según una pseudológica que en realidad es disfuncional (Beltrame, 1996: 44-46). En ambos casos esto se puede decir de la sociedad (rusa o filipina, respectivamente) en la cual, en teoría, un grupo determinado tiene el poder porque es culto. En el caso de Gogol son los terratenientes nobles, en el caso de Rizal son los españoles que viven en Filipinas y sus familias. Y ambos autores, burlándose de la pseudológica del sistema, en la cual quienes ostentan el rol de líderes en realidad no tienen la preparación necesaria, causan “un shock estético y, después, ético y gnoseológico" (Beltrame, 1996: 55).

Esto no es simplemente sátira. Para Gogol -como subraya Beltrame (1996: 13-15)- es una típica “visión grotesca de la realidad”. Esto le da la fama al mismo Gogol que es a la vez su perdición, porque él, no teniendo otra posibilidad de ver el mundo, no puede hacer evolucionar los elementos de personalidad presentes en Chíchikov (Mann, 1996: 321) y, por consiguiente, no puede realizar su proyecto de escribir una continuación de $\mathrm{Al}$ mas muertas, en la cual Chíchikov salga purificado por las penas. Es cierto que Gogol quemó la segunda parte del poema, la cual debía corresponder al Purgatorio de Dante, y terminó su carrera como escritor (Zen’kovsky, sin año: 251). Según Beltrame (1996: 83-84), Gogol va más allá de la sátira, porque no se limita a la crítica social sino que describe problemas espirituales profundos y entra en crisis como escritor debido a su propia crisis de fe.

Tampoco sería justificado calificar a Noli me tangere simplemente como una obra satírica. El autor reconoce que no hay respuestas inequívocas a los problemas descritos en la novela. En el prólogo A mi Patria Rizal (1983: 21) escribe, dirigiendo la palabra a su país, que según él, tiene "un cáncer social": "Deseando tu salud, que es la nuestra, y buscando el mejor tratamiento, haré contigo lo que con sus enfermos los antiguos: exponíanlos en las gradas del templo, para que cada persona que viniese de invocar a la Divinidad les propusiese un remedio”. Como dice E. San Juan, Jr. (1971: 
15-16), la sátira necesita una medida pero esa medida aquí no la hay -exactamente porque Rizal no tiene una posición clara. Por eso Noli me tangere es un "Bildungsroman" (novela de aprendizaje) en la cual el protagonista no aprende nada (San Juan, 1984: 37; cursiva de E. San Juan, Jr.). Por consiguiente, la novela es polifónica como las novelas de Dostoevsky no hay una posición inequívoca del autor sino una pluralidad de posiciones que coexisten (Castroverde, 2013: 10). Como en Almas muertas, la visión grotesca de la realidad conduce al lector más allá de una posición clara del autor, la que sería la posición satírica.

\section{El aspecto macabro}

El elemento macabro es una forma en la que en ambas obras se manifiesta la visión grotesca de la realidad; es decir, el contacto entre los vivos y los muertos que muestra la falta de respeto por parte de los vivos. Esto no tiene que ver con apariciones o visiones extraordinarias, en las cuales los muertos se inmiscuyen en el mundo de los vivos, sino que describe realísticamente cómo los vivos, siguiendo bajos intereses, se adentran en el mundo de los muertos. Así pues, propongo llamar a ese fenómeno realismo macabro, porque exactamente los hechos macabros muestran cuán perversa es la realidad descrita.

Parece que el papel particular de la muerte y los muertos como símbolo de la desdicha del país en Rizal tiene una de sus fuentes precisamente en Gogol. En particular, Gogol se refiere a la idea de Dante de usar el otro mundo como espejo del mundo real para criticar lo que verdaderamente sucede en su país. En 1836, estando en París, Gogol cuenta en una carta que, escribiendo parágrafos de Almas muertas, imagina toda la realidad de Rusia (Opul'skaia, 1984: 309). Tal como Dante escribe una enciclopedia de la vida medieval en Italia, Gogol compone un símil de la vida rural en Rusia (Alexandrov, 2010: 13-15). Almas muertas es una obra que tiene importancia para la humanidad entera, pero es primariamente un poema descriptivo de la realidad de Rusia (Mann, 1996: 248). Y, como Dante, Gogol escribe primero sobre los infernos de esa vida, por los cuales viaja Chíchikov en sus encuentros con terratenientes siempre peores. Después, Gogol quiere hablar del camino de purificación de Chíchikov (Alexandrov, 
2010: 18-19). Uno de los principales males de la vida en Rusia muy señalado por sus contemporáneos, la servidumbre, es criticado por Gogol no políticamente, ni describiendo los sufrimientos de los campesinos, sino a través de la imagen de las "almas muertas". Esa imagen da el título al poema y articula su trama. Tiene un significado bien concreto: era común llamar "almas" a los muzhiki (contadinos siervos) que poseía un terrateniente. Y lo que Chíchikov quiere comprar son exactamente las "almas muertas", es decir, a los campesinos que han muerto recientemente y, por eso, todavía aparecen en los registros oficiales como vivos (Gogol, 1984: 31). Ese motivo se desarrolla en el poema con motivos sombríos y una crítica social radical. Ya en la primera conversación con Manilov, en la cual Chíchikov habla de su intención de comprar "almas muertas", le dicen que muchos campesinos han fallecido después de la última revisión ${ }^{5}$, pero no saben cuántos (Gogol', 1984: 32). Otro terrateniente, Pliushkin, un avaro y misántropo, cuenta que han muerto 80 campesinos por causa de una epidemia (Gogol, 1984: 121).

Hay humor macabro en el diálogo en el cual Chíchikov intenta convencer a la terrateniente Korobochka de que le venda las "almas muertas". Ella no quiere venderlas porque piensa que, de repente, Chíchikov paga demasiado poco (Gogol, 1984: 51). Luego dice que sería mejor hablar con otros mercaderes para averiguar por cuánto dinero ellos estarían dispuestos a comprar campesinos difuntos. Y cuando Chíchikov pregunta para qué alguien podría comprar muzhiki muertos, ella contesta que "puede ser, en la economía de cualquier manera, en algún caso serán útiles” (Gogol, 1984: 52). A eso Chíchikov reacciona con sarcasmo y dice que lo único para lo que podrían ser útiles los muertos sería para ponerlos en el jardín de noche para ahuyentar a los gorriones. Korobochka entiende que esa propuesta es muy macabra y contesta: "iSea con nosotros la fuerza de la Cruz! iQué horrible es lo que dices!” y hace la señal de la cruz (Gogol, 1984: 53).

Es cómico cuando otro terrateniente, Sobakevich, regatea con Chíchikov el precio de los campesinos muertos y declara que son caros porque tienen

\footnotetext{
${ }^{5}$ Cada año se contaban los campesinos y se elaboraban registros oficiales, según los cuales se determinaba cuántos campesinos poseía un terrateniente y, por consiguiente, cuánto dinero tenía que pagar como impuesto. Los campesinos que morían después de una revisión se quedaban en el conteo hasta la próxima revisión.
} 
cualidades de buenos trabajadores, mientras que los campesinos vivos son "moscas, no hombres" (Gogol, 1984: 102).

Todo esto muestra cuán absurdo es el proyecto de comprar "almas muertas”. Chíchikov siente lo mismo, porque, no por casualidad, cuando habla por primera vez de ese proyecto con Manilov, lo hace con una "expresión rara o casi rara” (Gogol', 1984: 31). Por su parte, Manilov "quedó tan confuso y desorientado, que sólo miró” a Chíchikov (Gogol, 1984: 33).

También la censura reaccionó con confusión hacia el poema, ya que una parte del texto fue prohibida (Opul'skaia, 1984: 310). Además Gogol tuvo que cambiar el título, porque el censor le dijo que las ánimas son inmortales y que, por consiguiente, no hay "almas muertas”. Por esta razón, el título de la obra fue cambiado y, hasta la revolución de 1917, parecía ser más "inofensivo": Aventuras de Chíchikov o almas muertas (Opul'skaia, 1984: 310). Es cierto que, en parte, esto pasó por la idea absurda de comprar "almas muertas", o sea muzhiki, que en realidad ya están muertos pero que todavía aparecen en los registros como si estuvieran vivos, muestra cuán absurdo es y cómo insulta la dignidad humana cualquier posibilidad de comprar "almas". También da a entender lo absurdo de la burocracia según la cual no importa si una persona está viva o muerta, porque la verdad no está en la realidad, sino en los documentos.

Además la censura entendió que el tema de las "almas muertas" muestra lo agudo y peligroso de la disfunción de la sociedad rusa que, además de política o social, era también moral y espiritual. Las "almas muertas" del poema no son sólo los campesinos difuntos, sino también las almas de Chíchikov y de los terratenientes que han perdido su vida interior y espiritual por la "poshlost" o banalidad (Zen'kovsky, sin año: 58-59). O, como dice Andrei Biely (1934: 85), las figuras y aquello que las circunda se describen de tal manera que no tienen ninguna cualidad intrínseca, o sea son "polvo". Por eso Iuri Mann dice en un discurso que la risa en Gogol expresa "sentimientos tan profundos que a Gogol lo descifraban y le descifrarán siempre, mientras sea" (Krivonos, 2019: 207).

Así, Gogol describe las desdichas de Rusia y se burla de ellas. Él se mofa sobre todo de las clases altas o medias que deberían ser responsables del país y como tales tendrían que tener educación, pero, en realidad, sólo fingen tenerla. Esto no es sátira porque va más allá de la crítica político-social. Más bien pone de manifiesto que los males de la sociedad, y sobre todo 
de la servidumbre, son indicios de una crisis espiritual que se puede representar sólo con la ayuda de lo grotesco y, como su forma particular de expresión, de lo macabro.

Como Dante y Gogol, Rizal también escribe una enciclopedia, la de Filipinas en su tiempo. Y lo hace de manera dantesca porque describe infiernos por los cuales pasan los protagonistas: el infierno de los sacristanes maltratados por el cura del pueblo y sus cooperadores, hasta que uno de los sacristanes termina muerto y el otro huye (Rizal, 1983: 134-139); de su madre, Sisa (Rizal, 1983: 141-146; 147-152; 187-195; 366-377); de María Clara, que es constreñida a casarse con un hombre distinto de Crisóstomo y, como prefiere hacerse monja a contraer ese matrimonio, en el convento es violentada por un fraile (Rizal, 1983: 540-552; 581-582).

Y no hay acaso en la casa de Capitán Tiago "cuadros de las paredes, que representan asuntos religiosos como El purgatorio, El infierno, El juicio final, La muerte del justo, La muerte del pecador" (Rizal, 1983: 25). Exactamente los temas de la muerte y el juicio final tienen un gran papel en la novela. Y, por eso, el tema de la muerte se enriquece con otra nota macabra: la trama de la novela empieza alrededor del día de los muertos, el 2 de noviembre (Rizal, 1983: 112-117), y termina en los días de la Pascua, fiesta de la muerte y resurrección de Cristo (Rizal, 1983: 567). A inicios de noviembre, las personas piadosas del pueblo de San Diego discuten cuestiones del purgatorio (Rizal, 1983: 127-133) y de indulgencias (Rizal, 1983: 155-158). Sobre todo con la discusión sobre las indulgencias Rizal quiere hacer reír en vez de llorar. La gente pierde mucha fuerza de razón pensando en cómo usar mejor las indulgencias en vez de mejorar sus vidas por medio de técnica, medicina, etc. Esto se ve cuando llega Sisa a buscar a sus hijos pero las personas piadosas, que hablaban de indulgencias para sacar almas desde el sufrimiento después de la muerte no hacen nada para ayudar a una madre en sus sufrimientos terrenales (Rizal, 1983: 159-161).

En ese contexto, la falta de respeto frente a los muertos adquiere un significado especial. Como en Almas muertas, el tema de la muerte y la vida eterna está presente ya en el título: Noli me tangere es una cita del Evangelio según San Juan $(20,17)$ : después de su resurrección, Cristo dice a María Magdalena: “No me toques". En el contexto de Rizal, sin embargo, ese título se refiere al hecho de que los frailes tienen el poder en la esfera sexual y pueden "tocar" a las mujeres (Rizal, 1983 : 75; 551; 563-565; 581- 
582). También pueden “tocar” a los niños, es decir, golpearlos y torturarlos (Rizal, 1983: 188-189).

En gran medida, como en Almas muertas, justo el hecho de que "tocan" a los muertos forma la trama de la novela y muestra la monstruosidad de la realidad descrita por el autor: el Padre Dámaso no quiere que su hija natural María Clara se case con un filipino (Rizal, 1983: 563-564), por eso persigue a Crisóstomo y a su familia y manda a desenterrar incluso al difunto padre de Crisóstomo, don Rafael (Rizal, 1983: 120). Eso muestra que el poder de los frailes de "tocar" a los filipinos incluso va más allá de la muerte. Y, como el respeto frente a los muertos es un hecho antropológico fundamental (Rizal, 1983: 112), eso significa que el poder de los frailes es ilimitado.

Crisóstomo no quiere vengar la profanación de la tumba de su padre sino que hacer el bien para compensar ese mal (Rizal, 1983: 163). Sin embargo, en un momento de furia, cuando el mismo Padre Dámaso ofende también la memoria de don Rafael, Crisóstomo ataca al fraile, lo que conduce a su excomunión (Rizal, 1983: 332-335). La falta de respeto por los muertos es la culminación del poder absoluto y corrupto de los frailes y, por consiguiente, uno de los símbolos principales del mal que reina en Filipinas. Consiguientemente, es lógico que conduzca a la catástrofe.

Sin embargo, este tema no se presenta de manera exclusivamente trágica: el diálogo de los sepultureros, en el cual uno de ellos cuenta cuán fácil le es exhumar muertos, y también la manera en que ha exhumado el cuerpo de don Rafael, poco tiempo después de su muerte (Rizal, 1983: 114-117), hace pensar en los payasos en el cementerio en el Hamlet de Shakespeare (V, 1: 2003: 188-200; cf. Castroverde, 2013: 54).

También, como en Hamlet, ese diálogo está estrechamente ligado con la trama. En Hamlet precede la disolución trágica, en cambio en Noli me tangere el diálogo precede la ligación del nudo trágico. Esta sucede cuando el sepulturero le cuenta a Crisóstomo cómo exhumó el cuerpo de su padre. Pero aquí también en parte hay que reír en vez de llorar, sobre todo cuando el sepulturero le dice a Crisóstomo: "No os enfadéis, señor $<\ldots>$ no lo enterré entre los chinos. iMás vale ahogarse que estar entre los chinos, dije para mí, y arrojé el muerto al agua!” (Rizal, 1983: 121). El hecho de que el cuerpo de don Rafael no esté en el cementerio de los paganos tiene que ser, según él, un consuelo, ya que obviamente esté mejor para el hijo que la 
tumba del padre esté en un cementerio. Además, sabemos que las palabras del sepulturero son un subterfugio, porque en realidad arrojó el cuerpo en el agua sólo porque "el ataúd era pesado y el cementerio de los chinos está lejos” (Rizal, 1983: 115).

Rizal conecta crítica social, notas macabras y cómicas también en el capítulo que precede inmediatamente a la culminación de la novela con la rebelión y el arresto de los protagonistas, que se llama "La carta de los muertos y las sombras" (Rizal, 1983: 474). Se cuenta cómo los guardias civiles dijeron a Lucas "iBruto! iBurro! - y le dieron un empellón" (Rizal, 1983: 478). Elías y Lucas, de su parte, quieren participar en la conspiración para "arreglar [sus] cuentas con el cura" y "decir a los [guardias] civiles que nuestro padre tenía hijos” (Rizal, 1983: 474).

Al mismo tiempo, aquí también, Rizal se burla del hecho que los guardias civiles, los cuales tienen mucho poder, son estúpidos: cuando enumeran las "señas" de Elías, mencionan: "Estatura, alta según el alférez, regular según el padre Dámaso; color, moreno; ojos, negros; nariz, regular; barba, ninguna; pelo, negro", y, como "señas particulares": "Camisa negra, pantalón negro, leñador...” (Rizal, 1983: 478). No entienden que el hecho que Elías es supuestamente leñador no dice nada de su aspecto externo, ni que la ropa se puede cambiar, ni que de todas las señas que pertenecen a la fisionomía de Elías solo la nariz regular, en Filipinas, es verdaderamente una seña. Y cuando uno de los dos guardias muestra un poco de juicio, el otro lo pregunta: “¿Cómo eres guardia civil?” (Rizal, 1983: 479).

Aquí también la crítica satírica está conectada con un elemento macabro. Ya en el título "las sombras", es decir, las personas con las cuales se encuentran los guardias civiles, se conectan con "la carta de los muertos" (Rizal, 1983: 474-475). El tema de "la carta de los muertos" muestra que ha llegado un momento que decide los destinos de los protagonistas. No juegan a las cartas, y se dice explícitamente que "Lucas no invitó a nadie; no evocó a los muertos como manda la superstición” (Rizal, 1983: 477). Pero la hora de los muertos ha llegado (Rizal, 1983: 477) y se acercan los guardias civiles. En ese sentido, aquellos filipinos son los muertos que llegan, porque ellos han perdido su identidad. Sin embargo, como ya hemos visto, ese hecho no se presenta de manera trágica o polémica, sino como una burla por su estupidez. 


\section{Conclusión}

Así, Gogol y Rizal describen con realismo el sufrimiento de sus países, sobre todo la opresión de los pobres. Lo hacen, en parte, burlándose de la realidad, y especialmente de la falta de educación de las clases altas o medias y de los poderosos. Una forma artística específica e importante de representar la situación de Rusia y de Filipinas, respectivamente, es a la vez terrible y ridícula es el realismo macabro: tanto para la trama de Noli me tangere como de Almas muertas es central la transgresión desvergonzada, absurda y ridícula del mundo de los muertos por parte de los vivos.

\section{Referencias}

Alexandrov, L. G. (2010). Etapy Dantova puti v prostranstve "Miortvykh dush" N. V. Gogolia. Vestnik Cheliabinskogo gosudarstvennogo universiteta $40\left(\mathrm{~N}^{\mathrm{O}} 4\right), 14-21$.

Bakhtin, Mikhail M. (1984). Problems of Dostoevsky's Poetics. Edited and Translated by Caryl Emerson. Introduction by Wayne C. Booth. Minneapolis-London: University of Minnesota Press.

Beltrame, Franca. (1996). Teoria del Grottesco. Con un'esemplificazione nel racconto di N. V. Gogol' Il naso. Monfalcone: Edizioni della Laguna.

Biely, Andrei. (1934). Masterstvo Gogolia: Issledovanie. MoskvaLeningrad: Gosudarstvennoe izdatel'stvo khudozhestvennoi literatury.

Castroverde, Aaron C. (2013). José Rizal and the Spanish Novel. Tesis de Doctorado en el Department of Romance Studies in the Graduate School of Duke University.

Dostoevsky, Fyodor M. (1972-1990). Polnoe sobranie sochinenii $v 30$ tomakh. Leningrad: Nauka.

Giménez Gaballero, Ernesto. (1971). Rizal. Madrid: Publicaciones Españolas.

Gogol, Nikolai V. (1984). Sobranie sochineniy v vos'mi tomakh: Tom V. Moskva: Pravda.

Holquist, Michael. (1984). The Gaps in Christology: The Idiot. En Robert L. Jackson (ed.). Dostoevsky: New Perspectives (pp. 126-144). Eaglewood Cliffs, N.J.: Prentice Hall. 
Kholkina, A. S. (2016). Pervyi perevod "Miortuykh dush" N. V. Gogolia na angliiskii iazyk: osobennosti peredachi realii. En Elektronnyi nauchnyi zhurnal $\mathrm{N}^{\circ}$ 4, 239-242. Recuperado de: https://elibrary.ru/ item.asp?id=26167253.https://elibrary.ru/item.asp?id=26167253

Krivonos, V. Sh. (2019). Iz zametok o Gogole. En D. M. Magomedova, V. B. Zuseva-Ozkan, O. V. Fedunina (ed.). Literaturoman(n)ia: K 9o-letiu Iuria Vladimirovicha Manna: Sbornik statei (pp. 207-217). Moskva: Rossiiskii gosudarstvennyi universitet.

Mann, Iuri V. (1996). Poetika Gogolia: Variatsii k teme. Moskva: "Coda".

Nikanorova, Iulia V. (2011). Nekotorye osobennosti pervogo nemetskogo perevoda poemy N. V. Gogolia "Miortvye dushi". En Vestnik Nauki Sibiri $\mathrm{N}^{\circ} 1$ (1), 590-598. Recuperado de: http://jwt.su/journal/article/ view/94/94.

Novikova, Elena G. (2016). "Nous serons avec le Christ": Roman F. M. Dostoevskogo "Idiot". Tomsk: Izd-vo Tomskogo universiteta.

Ocampo, Esteban A.de. (1960). Rizal as a bibliophile. Manila: Unesco National Commission of the Philippines.

Opul'skaia, L. (1984). Primechania: Miortvye dushi, Tom pervy. En Gogol', Nikolai Vasilyevich. Sobranie sochineniy v vos'mi tomakh: Tom $V$ (pp. 308-313). Moskva: Pravda.

Pushkin, Alexandr S. (1975). Sobranie sochineniy V: Romany, Povesti. Moskva: "Khudozhestvennaia Literatura".

Rizal, José. (1983). Noli me tangere. La Habana: Editorial Arte y Literatura.

San Juan, Jr., Epifanio. (1971). The Radical Tradition in Philippine Literature. Quezon City: Manlapaz.

. (1984). Towards a People's Literature: Essays in the Dialectics of Praxis and Contradiction in Philippine Writing. Quezon City: University of the Philippines Press.

. (2010). Sisa's Vengeance: José Rizal/ Woman/ Revolution. Connecticut: Philippines Cultural Studies Center.

Shakespeare, William. (1967). Macbeth. Edited by G. K. Hunter. London: Penguin Books. (2003). Hamlet: Fully annotated, with an Introduction by Burton Raffel. With an essay by Harold Bloom. New Haven and London: Yale University Press. 
Turguéniev, Iván S. (1964). Sochinenia Tom VIII: Nakanune, Gamlet $i$ Don-Kikhot, Otsy i deti. Moskva-Leningrad: Nauka.

Zaide, Gregorio F./ Zaide, Sonia M. (1984). José Rizal: Life, Works and Writings of a Genius, Writer, Scientist and National Hero. Mandaluyong, Metro Manila: National Book Store.

Zen'kovsky, V. (sin año). N. V. Gogol'. París: YMCA-Press. 